Marquette University

e-Publications@Marquette

$12-2-2009$

\title{
Isolation and X-ray Structural Characterization of a Dicationic Homotrimer of 2,3,6,7-tetramethoxy-9,10-dimethylanthracene cation radical
}

Matthew J. Modjewski

Marquette University

Ruchi Shukla

Marquette University

Sergey Lindeman

Marquette University, sergey.lindeman@marquette.edu

Rajendra Rathore

Marquette University

Follow this and additional works at: https://epublications.marquette.edu/chem_fac

Part of the Chemistry Commons

\section{Recommended Citation}

Modjewski, Matthew J.; Shukla, Ruchi; Lindeman, Sergey; and Rathore, Rajendra, "Isolation and X-ray Structural Characterization of a Dicationic Homotrimer of 2,3,6,7-tetramethoxy-9,10-dimethylanthracene cation radical" (2009). Chemistry Faculty Research and Publications. 544.

https://epublications.marquette.edu/chem_fac/544 
Marquette University

e-Publications@Marquette

\section{Department of Chemistry Faculty Research and Publications/College of Arts and Sciences}

This paper is NOT THE PUBLISHED VERSION.

Access the published version at the link in the citation below.

Tetrahedron Letters, Vol. 50, No. 48 (2009, December 2): 6687-6690. DOI. This article is (C) Elsevier and permission has been granted for this version to appear in e-Publications@Marquette. Elsevier does not grant permission for this article to be further copied/distributed or hosted elsewhere without the express permission from Elsevier.

\section{Isolation And X-Ray Structural Characterization of a Dicationic Homotrimer of 2,3,6,7-Tetramethoxy-9,10- Dimethylanthracene Cation Radical}

Matthew J. Modjewski

Department of Chemistry, Marquette University, Milwaukee, WI, USA

Ruchi Shukla

Department of Chemistry, Marquette University, Milwaukee, WI, USA

Sergey V. Lindeman

Department of Chemistry, Marquette University, Milwaukee, WI, USA

Rajendra Rathore

Department of Chemistry, Marquette University, Milwaukee, WI, USA 


\section{Abstract}

Electrochemical oxidation of 2,3,6,7-tetramethoxy-9,10-dimethylanthracene (1) showed that it undergoes a highly reversible electrochemical oxidation ( $E_{\mathrm{ox}}=0.81 \mathrm{~V}$ vs SCE) and forms a modestly stable cation-radical salt in solution. X-ray crystallography established that $\mathbf{1}^{+}$. SbCl6- crystallizes as a (centrosymmetric) dicationic homotrimer via a close cofacial association of a pair of cationic and one neutral molecule of 1 with an interplanar separation of $\sim 3.2 \AA$. The structure of the dicationic homotrimer was also reproduced by DFT calculations. Furthermore, the structure of a dicationic spiro adduct, formed by a slow decomposition of a solution of $\mathbf{1}^{+}$. SbCl6-, was also established by X-ray crystallography.

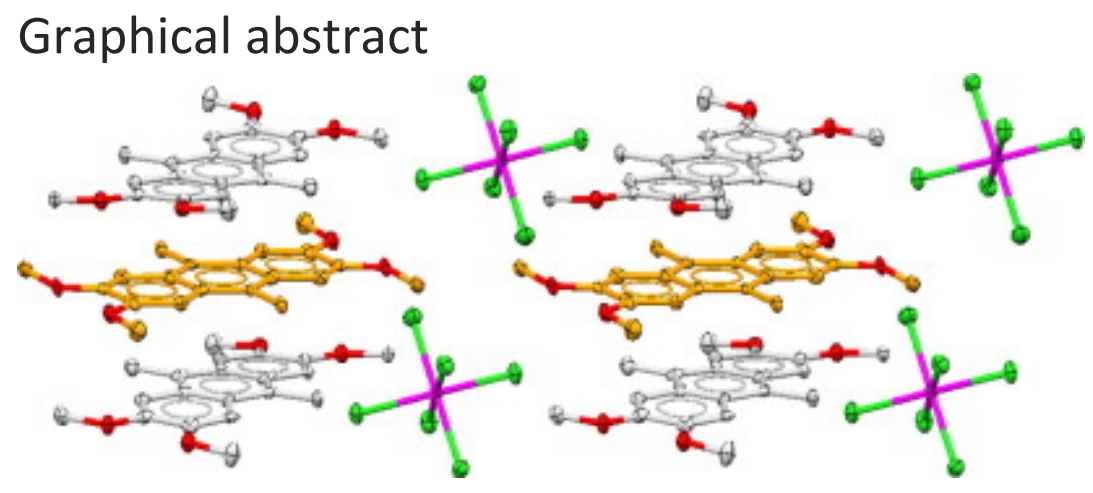

The stable organic cation radicals are not only critical reaction intermediates when (poly)aromatic electron donors are exposed to various oxidants or subjected to different electrochemical, photoinduced, and radiolytic (activation) methodologies, ${ }^{1,2,3}$ but they also pertain directly to the contemporary interest in organic materials science for molecular devices such as electrical and photoconductors, ferromagnets, sensors, and optical and electrochemical switches. 4, 5, 6, 7

Our continued interest in the design and synthesis of various (poly)aromatic hydrocarbons (such as substituted benzenes, naphthalenes, anthracenes, pyrenes, poly- $p$-phenylenes, and hexa-perihexabenzocoronenes), ${ }^{7}$ which form stable cation radicals (or hole carriers) prompted us to examine the possibility of isolation and X-ray crystallographic characterization of the cation radical of 2,3,6,7tetramethoxy-9,10-dimethylanthracene (1), ${ }^{8}$ whose derivatives have been extensively explored for various modern materials ${ }^{9}$ owing to the potential applications in the emerging areas of molecular electronics and nanotechnology. ${ }^{10}$

Herein, we now report that anthracene 1 can be quantitatively oxidized to its cation radical using either a stable aromatic oxidant ${ }^{11}$ or an inorganic oxidant such as $\mathrm{NO}^{+} \mathrm{SbCl6}^{-12}{ }^{12}$ The cation radical of 1 was found to be stable at low temperatures and allows the isolation of single crystals of a unique dicationic homotrimer, formally represented as a sandwich of a neutral molecule of $\mathbf{1}$ between the two cationic molecules of $\mathbf{1}^{+}$., as established by X-ray crystallography and corroborated by DFT calculations. Moreover, it is shown that the cation radical of anthracene 1 undergoes a slow multi-step transformation to a novel dicationic spiro product $\left(5^{2+}\right.$.), at room temperature, whose structure was also determined by X-ray crystallography. The details of these preliminary findings are discussed herein. 
The tetramethoxydimethylanthracene 1 was readily obtained by a simple condensation of 1,2dimethoxybenzene with acetaldehyde in a mixture of sulfuric acid and acetic acid at $0{ }^{\circ} \mathrm{C}$, that is, Eq. $1 .^{8}(1)$

The structure of anthracene 1 was established by ${ }^{1} \mathrm{H} /{ }^{13} \mathrm{C}$ NMR spectroscopy and was further confirmed by X-ray crystallography (see Fig. 1). In the crystals, the molecules of anthracene 1 occupy a crystallographic inversion center and have an ideal planar geometry. Moreover, the molecules of $\mathbf{1}$ form layers along the crystallographic ' $a b^{\prime}$ ' plane, and within these layers, neighboring parallel anthracene moieties are separated at van der Waals distances of $\sim 3.4 \AA$. Based on the observation of the limited $\pi, \pi$-overlap of the molecules of 1 in the layers, it is suggested that the crystal packing is largely dominated by $\mathrm{C}-\mathrm{H} \cdots \pi$ contacts (see Fig. 1 ).

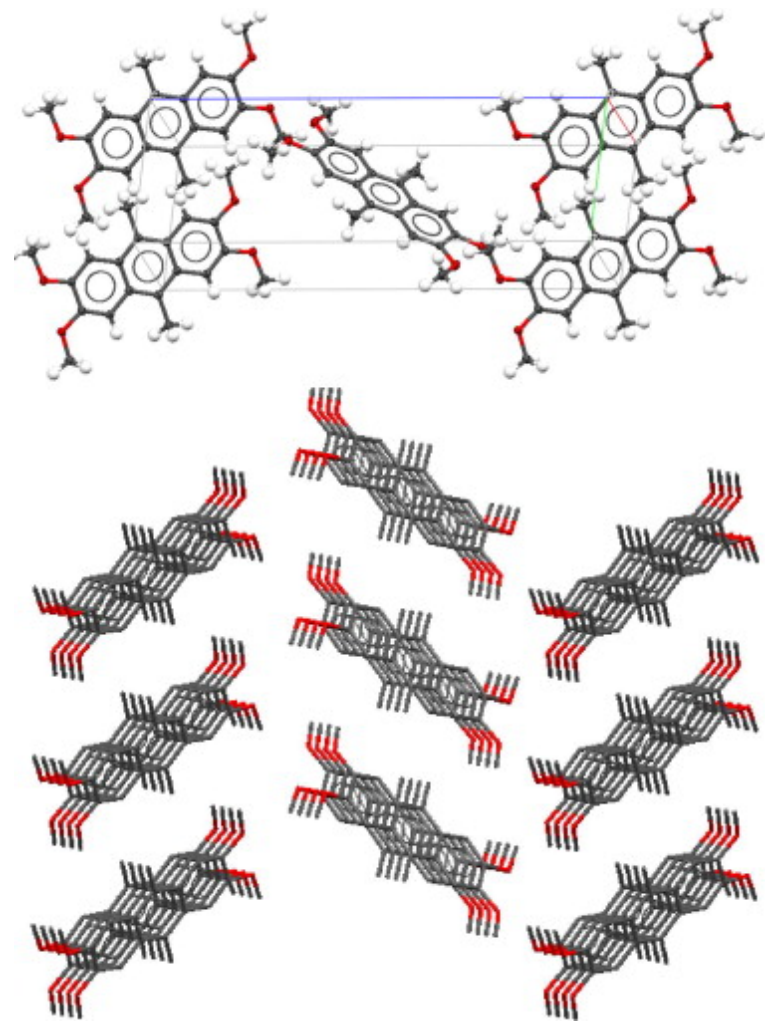

Figure 1 . The unit cell of anthracene 1 showing the limited $\pi, \pi$-overlap between the molecules of 1 (top) and its extended packing arrangement in the crystals (bottom) largely dominated by $\mathrm{CH}-\pi$ contacts.

The electron donor strength and the initial indication of the cation radical stability of 1 were evaluated by electrochemical oxidation at a platinum electrode as a $1 \times 10^{-3} \mathrm{M}$ solution in dichloromethane containing $0.1 \mathrm{M} n-\mathrm{Bu}_{4} \mathrm{NPF}_{6}$ as the supporting electrolyte. The cyclic voltammograms of 1 (Fig. 2) consistently met the reversibility criteria at various scan rates of 50-600 mV/s, as they all showed cathodic/anodic peak current ratios of $i_{\mathrm{a}} / i_{\mathrm{c}}=1.0$ (theoretical) as well as the differences between anodic and cathodic peak potentials of $E_{\mathrm{pa}}-E_{\mathrm{pc}}=70 \mathrm{mV}$ at $22^{\circ} \mathrm{C}$. The reversible oxidation potential of 1 ( $E_{\mathrm{ox}}=0.81 \mathrm{~V}$ vs SCE) was calibrated with added ferrocene ( $E_{\mathrm{ox}}=0.45 \mathrm{~V}$ vs SCE) as an internal standard. It is also noted that under similar conditions as mentioned above, the parent 9,10- 
dimethylanthracene undergoes an electrochemical oxidation at $E_{\mathrm{ox}}=1.16 \mathrm{~V}$ versus SCE owing to the absence of 4 electron-donating methoxy groups.

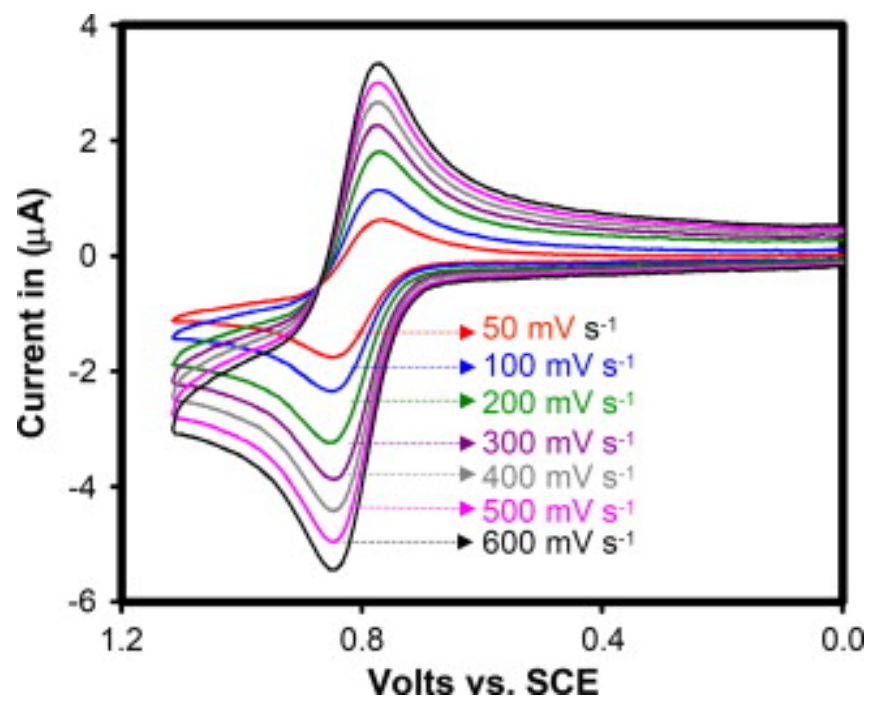

Figure 2. Cyclic voltammograms of $1 \times 10^{-3} \mathrm{M} 1$ in $\mathrm{CH}_{2} \mathrm{Cl}_{2}$ containing $0.1 \mathrm{M}$ tetra- $n$-butylammonium hexafluorophosphate $\left[(n-\mathrm{Bu})_{4} \mathrm{NPF}_{6}\right]$ at $22{ }^{\circ} \mathrm{C}$ at scan rates between 50 and $600 \mathrm{mV} \mathrm{s}^{-1}$.

The electrochemical reversibility and relatively low oxidation potential of $\mathbf{1}$, prompted us to generate its cation radical by chemical oxidation using a stable aromatic cation-radical ( $\mathrm{MA}^{+}$. SbCl6-; $E_{\text {red }}=1.11 \mathrm{~V}$ vs SCE) as a one-electron oxidant. ${ }^{11}$ Thus Figure 3 shows the spectral changes attendant upon an incremental addition of sub-stoichiometric amounts of 1 to a $3.4 \times 10^{-5} \mathrm{M} \mathrm{MA}^{+}$. $\left[\lambda_{\max }(\log \varepsilon)=518 \mathrm{~nm}\right.$ (3.86)] in dichloromethane at $22^{\circ} \mathrm{C}$. It is noted that the formation of green-colored $\mathbf{1}^{+}$. (i.e., increase in the absorbance at $700 \mathrm{~nm}$ ) and concomitant disappearance of $\mathrm{MA}^{+}$. (i.e., decrease in the absorbance at $518 \mathrm{~nm}$ ) was complete after the addition of 1 equiv of 1 ; and the resulting highly structured absorption spectrum of $1^{+} .\left[\lambda_{\max }=277,387,409(\log \varepsilon=4.61), 497,473,627\right.$, and $\left.706 \mathrm{~nm}\right]$ remained unchanged upon further addition of neutral 1 (i.e., Eq. 2). Furthermore, the presence of (multiple) welldefined isosbestic points (i.e., $\lambda=294,334,503$, and $508 \mathrm{~nm}$ ) in Figure 3 attest to an uncluttered character of electron transfer from 1 to $\mathrm{MA}^{+}$. (i.e., Eq. 2).(2)

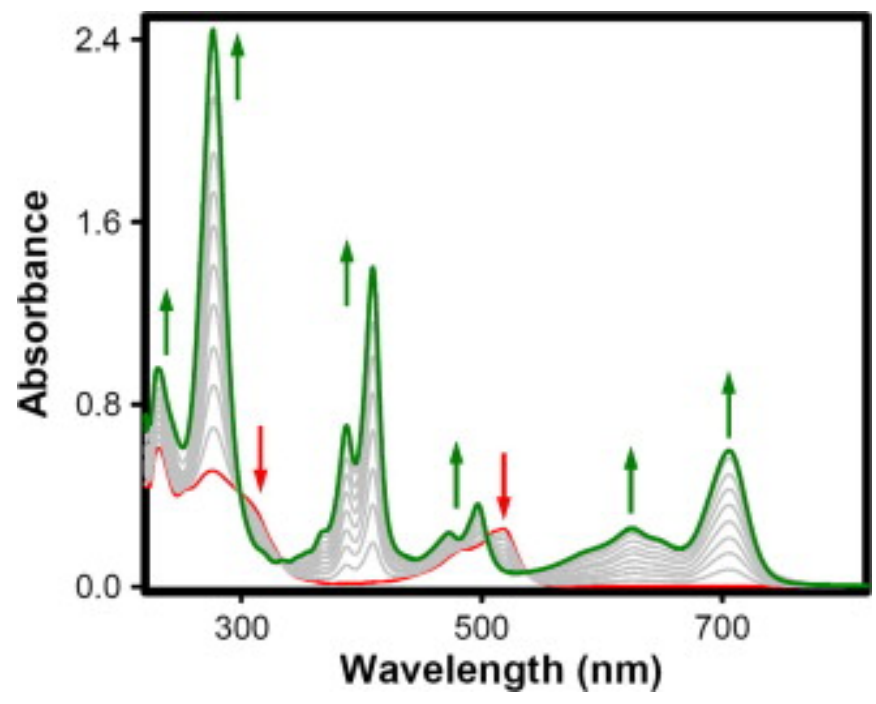


Figure 3. Spectral changes observed upon the reduction of $3.4 \times 10^{-5} \mathrm{M} \mathrm{MA}^{+}$. (red line) by addition of sub-stoichiometric increments of $1.0 \times 10^{-3} \mathrm{M} 1$ to its radical cation (gray lines) in anhydrous dichloromethane at $22^{\circ} \mathrm{C}$. The final plot (green line) of $\mathbf{1}^{+}$. obtained after the addition of 1 equiv of 1 which remained unchanged upon further addition of neutral 1.

It is also noted that the $\mathbf{1}^{+}$. did not show either the self-aggregation (i.e., pimer formation) ${ }^{13}$ or the formation of dimer cation radical [i.e., $\mathbf{1 + 1} \leftrightarrow(1) 2+\cdot$ ] in the presence of excess neutral 1 in dichloromethane solutions, as judged by the singular absence of any new absorption band in the near infrared region. ${ }^{13}$ The dichloromethane solution of the cation radical of anthracene 1 showed modest stability at ambient temperatures but was stable for several days at $-10{ }^{\circ} \mathrm{C}$, as discerned by the periodic monitoring of the solutions of $\mathbf{1}^{+}$. by UV-vis spectroscopy.

In order to isolate crystalline salts of $\mathbf{1}^{+}$, a solution of sufficient amounts of $\mathbf{1}^{+}$. was prepared by chemical oxidation using nitrosonium hexachloroantimonate $\mathrm{e}^{12}$ as a $1-\mathrm{e}^{-}$oxidant according to the stoichiometry in Eq. 3.(3)

Thus, a solution of 1 in anhydrous dichloromethane was added to crystalline NO+SbCl6- under an argon atmosphere at $\sim 0{ }^{\circ} \mathrm{C}$. The gaseous nitric oxide produced was entrained by bubbling argon through the solution to yield a dark green solution, which upon spectro-photometric analysis indicated the formation of $\mathbf{1}^{+}$. SbCl6- (see Fig. 3). Repeated attempts to isolate single crystals of $\mathbf{1}^{+}$. SbCl6- by a slow diffusion of toluene or hexane into the solution of $\mathbf{1}^{+}$. in dichloromethane, during a period of 4 days at $-10^{\circ} \mathrm{C}$, did not result into suitable single crystals. However, a solution of a 1:1 mixture of neutral 1 and $\mathbf{1}^{+}$. SbCl6- in dichloromethane afforded dark-colored crystals, suitable for X-ray crystallographic studies, by a slow diffusion of hexanes at $-10{ }^{\circ} \mathrm{C}$.

The crystal structure of 2,3,6,7-tetramethoxy-9,10-dimethylanthracene (1) cation radical revealed that it forms isolated (centrosymmetric) dicationic homotrimers resulting from a close cofacial association of a pair of cationic $\mathbf{1}^{+}$. SbCl6- and one neutral molecule of $\mathbf{1}$ (see Fig. 4) with an interplanar distance of $\sim 3.2 \AA$, which is considerably shorter than the van der Waal's contact ( 3.4 $\AA$ ). Within a homotrimer, the central anthracene ring is found to be completely planar whereas the two outer anthracene molecules are bent inward by $\sim 7^{\circ}$. (see Fig. 4). Unfortunately, the limited precision of the structure of the dicationic homotrimer (i.e., esd = $1 \mathrm{pm}$ ) did not allow an accurate estimation of the distribution of the cationic charges onto the three anthracene molecules. However, a pair of counter anions (SbCl6-) associated with each homotrimer are located in proximity to the outer anthracene molecules than to the central anthracene molecule (see Fig. 4A), and thus suggest that the charge distribution may not be similar amongst the three anthracene moieties in the dicationic homotrimer. Calculation of the molecular structure of the dicationic (triplet) homotrimer using DFT calculations at the B3LYP/6-31G* level reproduced a similar arrangement of the three anthracene molecules. Furthermore, an examination of the bond length changes in various anthracene molecules (see Fig. S1 and Table S1A-C in the Supplementary data) showed that the cationic charge was largely ( 70\%) localized onto the outer (bent) anthracene molecules whereas the central (planar) anthracene molecule contained only a partial cationic charge $(\sim 30 \%){ }^{14}$ 

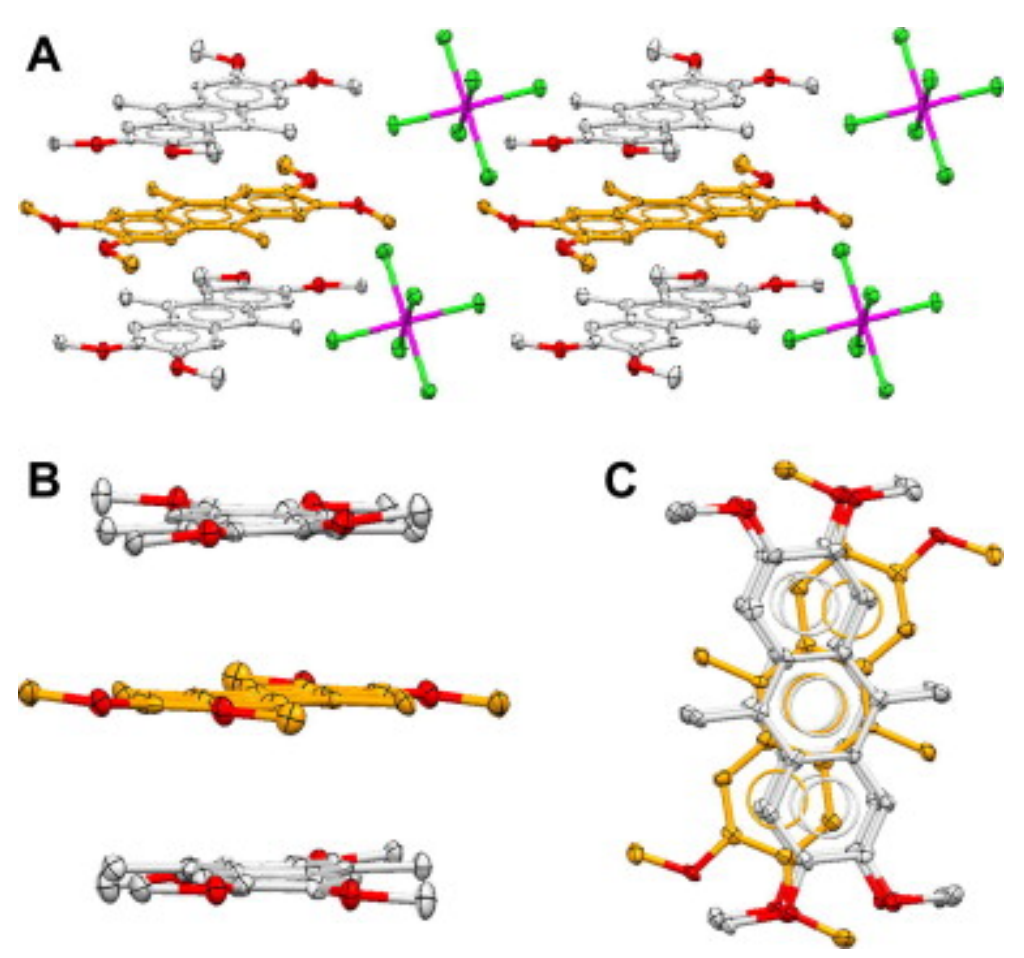

Figure 4. Crystal structure of the tetramethoxydimethylanthracene cation radical with the packing diagram (A) showing that it crystallizes as a centrosymmetric homotrimer (B and $\mathbf{C}$ ) with a pair of cationic charges [(SbCl6-)2]. The thermal ellipsoids are shown in $50 \%$ probability and the hydrogens and solvent molecules $\left(\mathrm{CH}_{2} \mathrm{Cl}_{2}\right)$ are omitted for the sake of clarity.

The instability of $\mathbf{1}^{+} . \mathrm{SbCl} 6$ - at ambient temperatures was further probed by allowing its dichloromethane solution to stand for a period of 1-2 days at $22^{\circ} \mathrm{C}$. After which time, the solution deposited shiny dark-colored needles which were analyzed by X-ray crystallography as follows.

The X-ray structure in Figure 5 showed that the decomposition of a dichloromethane solution of $\mathbf{1}^{+}$ . SbCl6- at $22{ }^{\circ} \mathrm{C}$ produces a (doublet) dicationic spiro adduct [ $5^{2+}$. (SbCl6-)2] via a multi-step transformation. The decomposition of $\mathbf{1}^{+} . \mathrm{SbCl6}$ - to the dicationic spiro adduct in Figure 5 can be reconciled by a sequence of transformations as elucidated in Scheme 1.

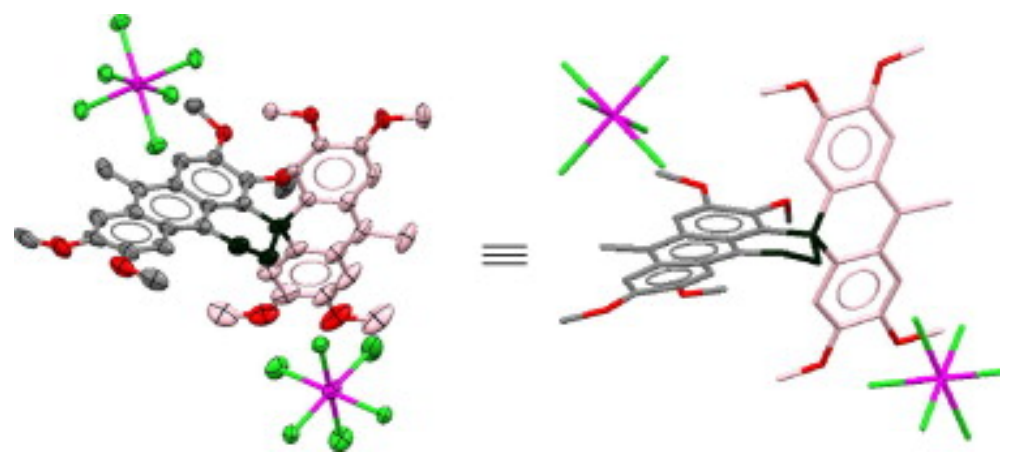

Figure 5. ORTEP (left) and stick (right) diagrams of a (doublet) dicationic spiro adduct [5 ${ }^{2+}$. (SbCl6-)2] formed via the decomposition of a $\mathrm{CH}_{2} \mathrm{Cl}_{2}$ solution of $1^{+}$. SbCl6- at $22^{\circ} \mathrm{C}$. The thermal ellipsoids are shown in $30 \%$ probability and the hydrogens and solvent molecules $\left(\mathrm{CH}_{2} \mathrm{Cl}_{2}\right)$ are omitted for the sake of clarity. 


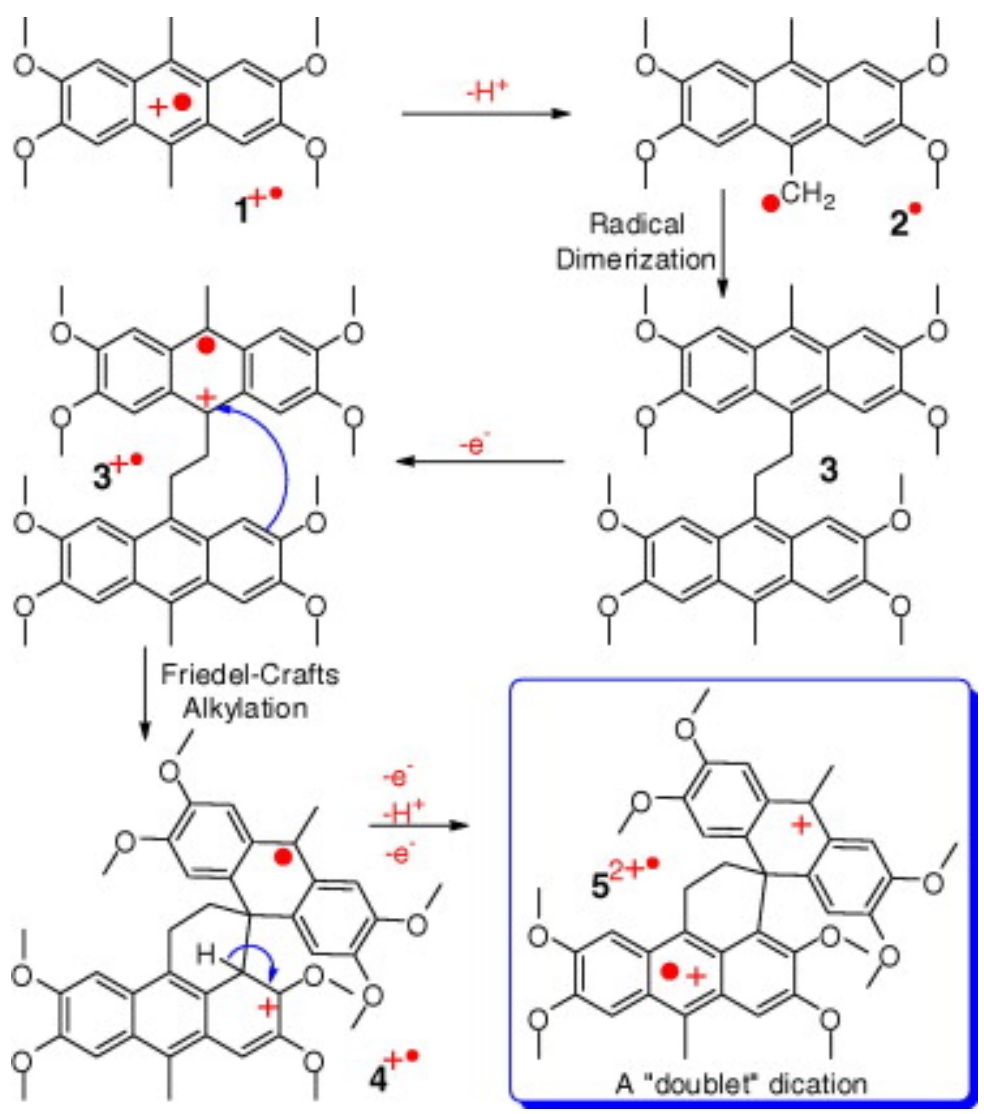

Scheme 1. Proposed mechanism for the formation of dicationic spiro adduct $\left(5^{2+}\right.$.) by a decomposition of a $\mathrm{CH}_{2} \mathrm{Cl}_{2}$ solution of $1^{+}$. $\mathrm{SbCl} 6-$ at $22^{\circ} \mathrm{C}$.

The 1-e $\mathrm{e}^{-}$oxidation of a methylbenzene to its cation radical is known to enhance the acidity of methyl protons by several orders of magnitude. ${ }^{15}$ Thus, a loss of $\mathrm{H}^{+}$from $\mathbf{1}^{+}$. generates a benzyl-type radical 2

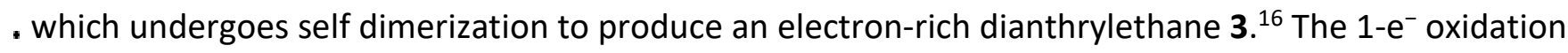
of $\mathbf{3}$ with $\mathbf{1}^{+}$. affords $\mathbf{3}^{+}$. which undergoes an efficient intramolecular Friedel-Crafts-type alkylation to form a distonic cation radical ${ }^{17} 4^{+}$.. A facile loss of a proton and a pair of electrons then furnishes the dicationic Spiro adduct $\left[5^{+} .\left(\mathrm{SbCl}_{6}\right)\right.$ )2] shown in Figure $5 .{ }^{18}$

In summary, we have demonstrated that the readily available 2,3,6,7-tetramethoxy-9,10dimethylanthracene (1) cation radical crystallizes as a dicationic homotrimer with the stoichiometry [(1)32+·(SbCl6-)2] as established by X-ray crystallography. The molecular structure of the dicationic homotrimer was reproduced by DFT calculations at B3LYP/6-31G* level which provided evidence that the charge distribution is dissimilar amongst the three anthracene moieties and the central anthracene molecule bears only a partial charge in the dicationic homotrimer. It was also shown that prolonged storage of $\mathbf{1}^{+} . \mathrm{SbCl} 6-$ at $22^{\circ} \mathrm{C}$ leads to its decomposition to a dicationic spiro adduct [5 ${ }^{2+}$. (SbCl6-)2] as established by X-ray crystal structure analysis. The formation of a stabilized dicationic homotrimer from 1 in solid state is unique in the light of the fact that generally aromatic cation radicals crystallize as dimeric cation radical where a single charge is evenly delocalized over both the aromatic rings. ${ }^{7,14}$ Studies are underway for a more comprehensive investigation of the structure modulation of the anthracene ring system for the preparation and study of a covalently linked homotrimers and their higher homologues. 


\section{Acknowledgment}

We thank the National Science Foundation for the financial support.

\section{Supplementary data}

Supplementary data. Synthetic details of 1, spectral data, and DFT calculation data for the dicationic homotrimer are available. Crystallographic data (excluding structure factors) for 1, [(1)32+·(SbCl6-)2], $\left[5^{2+}\right.$. (SbCl6-)2] have been deposited with the Cambridge Crystallographic Data Centre CCDC 747382, 747384, and 747384. Copies of the data can be obtained, free of charge, on application to CCDC, 12 Union Road, Cambridge CB2 1EZ, UK, (fax: +44-(0)1223-336033 or email: deposit@ccdc.cam.ac.uk).

\section{References and notes}

1 L. Eberson. Electron-Transfer Reactions in Organic Chemistry. Springer, New York (1987) 2 K. Yoshida. Electrooxidation in Organic Chemistry. The Role of Cation Radicals as Synthetic Intermediates. Wiley, New York (1984)

3 R. Rathore, J.K. Kochi. Adv. Phys. Org. Chem., 35 (2000), p. 193. and references cited therein 4_(a) Y. Shirota, H. Kageyama. Chem. Rev., 107 (2007), p. 953. (b) R.L. Carroll, C.B. Gorman. Angew. Chem., Int. Ed., 41 (2002), p. 4378

5 J.S. Miller, A.J. Epstein, W.M. Reiff. Science, 240 (1988), p. 40. and references cited therein

6_(a) C. Rovira. Chem. Rev., 104 (2004), p. 5289. (b) J.L. Segura, N. Martın, D.M. Guldi. Chem. Soc. Rev., 34 (2005), p. 31. (c)V.J. Chebny, R. Shukla, S.V. Lindeman, R. Rathore. Org. Lett., 11 (2009), p. 1939. and references cited therein

7_(a) M. Banerjee, R. Shukla, R. Rathore. J. Am. Chem. Soc., 131 (2009), p. 1780. (b) V.J. Chebny, T.S. Navale, R. Shukla, S.V. Lindeman, R. Rathore. Org. Lett., 11 (2009), p. 2253. and references cited therein

8 I.M. Davidson, O.C. Musgrave. J. Chem. Soc. (1963), p. 3154

9_(a) X.-Z. Zhu, C.-F. Chen. J. Am. Chem. Soc., 127 (2005), p. 13158. (b) X.-Z. Zhu, C.-F. Chen. J. Org. Chem., 70 (2005), p. 917. and references cited therein

10_(a) M.C. Petty, M.R. Bryce, D. Bloor (Eds.), Introduction to Molecular Electronics, Oxford Univ. Press, New York (1995). (b) H. Klauk (Ed.), Organic Electronics, Wiley-VCH, Weinheim (2006)

11 R. Rathore, C.L. Burns, M.I. Deselnicu. Org. Synth., 82 (2005), p. 1

12 R. Rathore, C.L. Burns, M.I. Deselnicu. Org. Lett., 3 (2001), p. 2887

13 It should be noted that the addition of up to 10 equiv of neutral 1 to the solution of $\mathbf{1}^{+}$. or increasing the concentration of $\mathbf{1}^{+}$. by 10 -fold did not show any change in its absorption spectrum. ${ }^{7}$

14_(a) Compare: P. Le Magueres, S.V. Lindeman, J.K. Kochi. Org. Lett., 2 (2000), p. 3567. (b)

S. Lee, B. Chen, D.C. Fredrickson, F.J. DiSalvo, E. Lobkovsky, J.A. Adams. Chem. Mater., 15 (2003), p. 1420

15 C.J. Schlesener, C. Amatore, J.K. Kochi. J. Am. Chem. Soc., 106 (1984), p. 7472

16_(a) Note that the 9,10-dimethylanthracene cation radical is known to produce the corresponding dianthrylethane via a radical intermediate akin to 2. See: V.D. Parker, L. Eberson. Tetrahedron Lett. (1969), p. 2839. (b) V.D. Parker, L. Eberson. Acta Chem. Scand., 24 (1970), p. 3542

17 S.H. Wadumethrige, R. Rathore. Org. Lett., 10 (2008), p. 5139. and references cited therein 18 Compare: H.D. Becker, D. Sanchez. J. Org. Chem., 44 (1979), p. 1787 